strictly limited overtime for young persons more than sixteen years of age and its prohibition for those less than sixteen, as well as prohibition of night work for a period of 11 hours, and it is considered essential that immediate steps be taken to give statutory protection to the unregulated young persons covered by the Report. It is recommended that the regulation of the hours of work of those employed in connexion with factories, docks and warehouses should be entrusted to the Factory Department of the Home Office and, for the remainder, to the local authorities responsible for administering the Shops Acts.

\section{Traffic in Women and Children in the East}

A Conference of Central Authorities in Eastern Countries on the Traffic in Women and Children in the East opened at Bandoeng, Java, on February 2, as the outcome of investigations in 1930-31 by the League of Nations' Commission of Enquiry into the Traffic in Women and Children in the East. This Commission established that the international traffic in Oriental women and girls in the Near, Middle and Far East is, in the aggregate, large. The bulk of this traffic is Asiatic women from one country to another, mainly in victims of Chinese race, Japanese, including Korean and Formosan, coming next in numerical importance, and other nationalities being very much less represented. Traffic in Occidental women to the East, with certain exceptions, chiefly in the Mediterranean Near East, has markedly decreased. The agenda of the Conference consisted of six points covering the chief suggestions of the report for closer collaboration between central and other authorities; and between authorities and voluntary organizations; the protection of migrants, especially minors, victims, or potential victims, of the traffic; the employment of women officials; the question of the continued existence of licensed or tolerated houses, which are the chief agents of internal and international traffic in the Indian and Pacific Oceans; and problems involved in the position of women of Russian origin in the Far East. Nine Governments, including the United Kingdom (Governments of the Straits Settlements, Federated Malay States and Hong Kong), China, France, India, Japan, the Netherlands, Portugal, Siam and the United States of America participated, as well as representatives of the International Criminal Police Commission.

\section{Exhibition of Chemical Engineering}

AN exhibition, Achema VIII, devoted to chemical technology, in which nearly three hundred firms have already arranged to take part, will be held in Frankfort-on-Main on July 2-11. Concurrent with the exhibition will be held the National Congress of German Chemists, the semi-centenary of the Verein Deutscher Chemiler, thereby providing the organizers of the exhibition with a unique opportunity of establishing the importance of the chemical engineer to the modern industrial community. The Hohenzollernplatz near to the University has been selected as the site of the exhibition, which will be housed in four separate buildings. In the first of these buildings, having a floor area of 125,000 square feet and subdivided into three sections, termed Halls I, II and II $a$ in the official foreword, will be shown scientific apparatus including measuring, regulating and laboratory equipment, technical plant constructed from non-metallic materials, as well as machines for the manufacture, machining and shaping of synthetic materials. Two buildings, namely Hall III, having a floor area of 20,000 square feet, and Hall IV, with a floor area of 100,000 square feet, will be used to display technical equipment on a large scale such as machines and complete plants for the chemical and associated industries and similar exhibits. The last building is again subdivided into two parts, namely Hall III $a$ with a floor area of 10,000 square feet which will be devoted to that part of the chemical industry engaged on the production of, and spinning of, artificial fibres, and Hall III $b$ with a floor space of 5,000 square feet in which will be shown the publications of the various German scientific associations and societies. Arrangements have also been made for special meetings, conducted tours, showing of industrial films, excursions for visitors to the exhibition. Further information can be obtained about the meeting by application to the Deutsche Gesellschaft für Chemisches Apparatewesen EV, Achema Bureau, Berlin W 35, Potsdamer Strasse $103 a$.

\section{Broadcasting in 1936}

A REview of the activities of the British Broadcasting Corporation during 1936 is given in the tenth annual report of the Corporation, which has recently been issued as a white paper (Cmd. 5406. London: H.M. Stationery Office. 6d. net). The year 1936 was conspicuous in the first instance because three successive kings were involved in turn in certain of the broadcast programmes. The report contains details of the outstanding items in a wide variety of programmes broadcast throughout the year, during which the home transmitters were in operation for 71,123 hours, of which the proportion of breakdown periods was 0.031 per cent. The corresponding aggregate time for the Empire transmitters was 16,577 hours, an increase of more than forty per cent on the figure for 1935. Apart from the maintenance of the stations and plant required for these services, the activities of the B.B.C. on the engineering side included the putting into service of the highpower transmitter at Lisnagarvey in Northern Ireland, the completion of a similar transmitter at Burghead. in the north of Scotland and the construction of a medium power transmitter at Beaumaris in Anglesey, which has been put into service in the current year. Good progress has also been made with large-scale extensions to the Empire Station at Daventry. These include the commencement of a third trans. mitter of considerably higher power than those now in operation ; together with the erection of additional masts for an improved aerial system, which is the outcome of experiments carried out at the Empire Station since it was first put into service in 1932. 